\title{
Plasmid-mediated colistin resistance mcr-1 in a clinical isolate of Escherichia coli ST19 in Algeria
}

\author{
Selma Bouheraoua ${ }^{1,2}$, Farida Assaous ${ }^{2}$, Nora Zourdani ${ }^{2}$, Naima Tahrat ${ }^{2}$, Hassiba Tali Maamar ${ }^{2}$ \\ ${ }^{1}$ Université d'Alger, Faculté de Médecine, Département de Pharmacie, Alger, Algeria \\ ${ }^{2}$ Laboratoire de Bactériologie Médicale et de Surveillance de La Résistance des Bactéries aux Antibiotiques, Institut \\ Pasteur d'Algérie. Route du petit Staoueli. Dely Ibrahim, Algiers, Algeria
}

\begin{abstract}
We describe the emergence of plasmid-mediated colistin resistance mcr-1 in a clinical isolate of Escherichia coli ST19. The strain was isolated from a urine sample of a 75-year-old male patient. The identification was carried out by an automated system. The antibiogram was performed according to CLSI recommendations. The colistin MIC was determined by broth micro-dilution according to CA-SFM/EUCAST criteria. The detection of mcr-1 was carried out by immunochromatographic test and PCR mcr-1. Genetic transfers and determination of the plasmid incompatibility group were made. The ST was carried out by MLST using the Pasteur scheme.

The strain has a high-level penicillinase resistance phenotype. It was susceptible to amikacin and resistant to gentamicin, tobramycin, fluoroquinolones, tetracycline, chloramphenicol, and cotrimoxazole. The strain was resistant to colistin (MIC $=4 \mu \mathrm{g} / \mathrm{ml})$.

The genetic transfer is given a colistin-resistant transconjugant. The plasmid carrying mcr-1 gene belongs to the incompatibility group IncHI2. The strain belongs to ST19. J Microbiol Infect Dis 2019; 10(4):222-224.
\end{abstract}

Keywords: Colistin resistance, mcr-1, Escherichia coli ST19

\section{INTRODUCTION}

Colistin, a polypeptide antibiotic, is showing renewed interest in the treatment of multidrugresistant Gram-negative bacilli. However, resistance appeared either by chromosomal mutations or by plasmid acquisition. The plasmid-mediated colistin resistance ( $m c r$ gene) was first described in 2015 [1]. Since then, several authors have reported the emergence of this mechanism in both veterinary medicine and human medicine [2]. The risk of transfer of $\mathrm{mcr}$ gene makes fearful its spread, especially if selection pressure by the polypeptides is exerted.

We describe the emergence of plasmidmediated colistin resistance mcr-1 in a clinical isolate of Escherichia coli sequence type (ST) 19.

\section{CASE}

In 2014, an E. coli strain was isolated from a urine sample of a 75-year-old male patient, diabetic and hypertensive, presenting an adenoma of the prostate. CBEU (a bacteriological urine test) was motivated by the presence of pollakiuria, urinary incontinence, and urinary burns.

The identification of the strain was carried out by the "Vitek 2 Systems". The antibiogram was performed according to CLSI recommendations [3].

Colistin minimal inhibitory concentration (MIC) was determined by broth micro dilution, reference technique recommended by CA-SFM / EUCAST (4), using the colistin sulfate powder and the cations-adjusted $\mathrm{MH}$ broth (CAMHB), the dilution range of colistin were from 0.016 to $128 \mu \mathrm{g} / \mathrm{ml}$.

The detection of mcr-1 was performed by immunochromatographic rapid test "NG-Test

Correspondence: Dr. Dr Selma Bouheraoua, Université d’Alger, Faculté de Médecine, Département de Pharmacie, Alger, Algeria Email: bouheraoua.selma@hotmail.fr

Received: 22 December 2019 Accepted: 23 August 2020

Copyright (C JMID / Journal of Microbiology and Infectious Diseases 2020, All rights reserved 
MCR-1" $®$ and confirmed by polymerase chain reaction (PCR) mcr-1 using primers; $\mathrm{F}$ : 5' GCAGCATACTTCTGTGTGGTAC 3', R: 5' TATGCACGCGAAAGAAACTGGC 3' [5].

In order to demonstrate that the resistance is carried by a plasmid, genetic transfers by conjugation in $E$. coli J5 Azide were made. Genetic transfer was followed by typing the plasmid to determine the incompatibility group.

The Sequence Type of the isolated strain was carried out by Multi Locus Sequence Typing (MLST) according to Pasteur scheme (bigsdb.pasteur.fr/ecoli/ecoli.html) by sequencing the genes: $\operatorname{din} B$, icd $A, p a b B$, polB, putP, $\operatorname{trp} A, \operatorname{trp} B$ and uid $A[6]$.

In addition, we conducted the search for genes for $\beta$-lactams resistance: penicillinases (blaTEM, blaSHV) and extended spectrum $\beta$-lactamase (blaCTXM1, blaCTXM2, blaCTXM8, blaCTXM9), for plasmid fluoroquinolones resistance (qnrA, qnrB, qnrS and aac 6 '-lb-cr) and we also search for class 1, 2 and 3 integrons.

Antibiotic susceptibility testing reveals a highlevel penicillinase resistance phenotype with

Table1. Comparison between the isolated strain in our case and strains described in the literature.

\begin{tabular}{|c|c|c|c|c|c|c|c|c|}
\hline Cases & Origin & ST & $\begin{array}{c}\text { MLST } \\
\text { scheme }\end{array}$ & $\begin{array}{c}\text { colistin } \\
\text { MIC } \\
(\mu \mathrm{g} / \mathrm{ml})\end{array}$ & ESBL & NDM & $\begin{array}{c}\text { Plasmid } \\
\text { carrying } \\
m c r-1\end{array}$ & Reference \\
\hline Our Case & Human (Urine) & $\begin{array}{l}\text { E. coli } \\
\text { ST19 }\end{array}$ & Pasteur & 4 & - & - & IncHI2 & \\
\hline Venezuela & Human (Feces) & $\begin{array}{l}\text { E. coli } \\
\text { ST19 }\end{array}$ & Pasteur & 4 & + & $\stackrel{+}{\text { NDM1 }}$ & Incl2 & (10) \\
\hline Brazil & Human (blood) & $\begin{array}{c}\text { E. coli } \\
\text { ST156* }\end{array}$ & Warwick & 4 & - & - & $\operatorname{lncX} 4$ & (11) \\
\hline Algeria & Human (sperm) & $\begin{array}{l}\text { E. coli } \\
\text { ST405 }\end{array}$ & Warwick & 8 & + & - & IncFIB & (8) \\
\hline Algeria & Human (urine) & $\begin{array}{l}\text { E. coli } \\
\text { ST405 }\end{array}$ & Warwick & 4 & + & - & l & (9) \\
\hline China & Animal (Duck) & $\begin{array}{c}\text { E. coli } \\
\text { ST156* }\end{array}$ & Warwick & l & + & $\stackrel{+}{\text { NDM5 }}$ & Incl2 & (12) \\
\hline Algeria & $\begin{array}{c}\text { Animal (Barbary } \\
\text { macaques) }\end{array}$ & $\begin{array}{l}\text { E. coli } \\
\text { ST405 }\end{array}$ & Warwick & 4 & + & - & l & (7) \\
\hline
\end{tabular}

*Corresponding to ST19 in Pasteur scheme: ST= Sequence type, MLST= Multi locus sequence typing, MIC= Minimal inhibitory concentration, $\mathrm{ESBL}=$ Extended-spectrum beta-lactamase, NDM= New Delhi Metallo-beta-lactamase.

\section{DISCUSSION}

Plasmid-mediated colistin resistance in $\mathrm{E}$ coli has already been described in Algeria in wild resistance to ampicillin, ticarcillin and piperacillin, intermediate resistance to cefazolin, susceptibility to amoxicillin / clavulanic acid, $3^{\text {rd }}$ and $4^{\text {th }}$ generation cephalosporins and carbapenems.

The strain is susceptible to amikacin and resistant to gentamicin, tobramycin, fluoroquinolones, tetracycline, chloramphenicol, sulfonamides, trimethoprim, cotrimoxazole and colistin with a MIC of $4 \mu \mathrm{g} / \mathrm{ml}$ (MICs breakpoint values CA-SFM / EUCAST: susceptible: $\leq 2$ $\mu \mathrm{g} / \mathrm{ml}$, Resistant: $>2 \mu \mathrm{g} / \mathrm{ml}$ ).

The results of rapid test "NG-Test MCR-1" $®$ and mcr-1 PCR were positives. The transconjugant obtained by conjugation was colistin resistant, with detection of $\mathrm{mcr}$-1gene by PCR demonstrating the transferability of this resistance. The plasmid carrying this gene belongs to Incompatibility Group IncHI2.

PCR revealed, also, the presence of the penicillinase gene blaTEM as well as the class 1 integron. The result of the MLST shows an $E$. coli ST19 genotype (dinB: 7, icdA: 37, pabB: 4, polB: 10 , putP: 26, $\operatorname{trpA}: 7, \operatorname{trpB}: 4$, uidA: 2). 
(https://enterobase.warwick.ac.uk/species/ecoli/ allele_st_search), while our isolate belongs to the ST 19 clone (bigsdb.pasteur.fr/ ecoli / ecoli.html) which corresponds to ST 156 of the Warwick data base.

The bibliography reports human cases of plasmid-mediated colistin resistance in $E$ coli ST19: In Venezuela, the strain was also producing a metallo-carbapenemase type NDM1 [10] and in Brazil, in this case the strain was susceptible to carbapenems [11]. Animal case have also been described in China in ducks [12].

In our case, we report the notion of eating frozen meat that may be the source of the contamination.

The plasmid carrying the mcr-1 gene belonged to incompatibility group IncHI2, already described in the literature $[13,14]$. Indeed, the plasmids most frequently encountered belong to incompatibility group Incl2, IncX4 and more rarely IncP, IncFII, IncHI1 and IncHI2 [2]

In table 1, we compare the mains results obtains with those of the literature

\section{Conclusion:}

The emergence of plasmid mediated colistin resistance raises fears of horizontal spread with a risk of therapeutic impasse if faced with a multidrug resistant bacterium. It is therefore imperative to monitor the emergence of this type of resistance in the laboratory, by the determination of colistin MIC, the performance of rapid diagnostic tests and $\mathrm{PCR}$.

\section{ACKNOWLEDGMENTS}

Declaration of Conflicting Interests: The authors declare that they have no conflict of interest.

\section{Funding: Not applicable REFERENCES}

1. Liu Y-Y, Wang Y, Walsh TR, et al. Emergence of plasmid-mediated colistin resistance mechanism MCR-1 in animals and human beings in China: a microbiological and molecular biological study. The Lancet Infectious Diseases. févr 2016;16(2):161-8.

2. Dortet L, Bonnin R, Jousset A, Gauthier L, Naas T. Émergence de la résistance à la colistine chez les entérobactéries: une brèche dans le dernier rempart contre la pan-résistance! Journal des Antiinfectieux. déc 2016;18(4):139-59.
3. CLSI. Performance standards for Antimicrobial Susceptibility testing. 28th ed. CLSI supplement M100.Wayne, PA: Clinical and Laboratory Standard Institute; 2018. (ISBN: 1-56238-839-8)

4. Enterobacteriaceae. In: CASFM / EUCAST: Société Française de Microbiologie Ed; 2018: p.36-43.

5. Chabou S, Leangapichart T, Okdah L, Le Page S, Hadjadj L, Rolain J-M. Real-time quantitative PCR assay with Taqman $\AA$ probe for rapid detection of MCR-1 plasmid-mediated colistin resistance. N Microb N Infect 2016; 13:71-4.

6. Jaureguy $F$, Landraud L, Passet $V$, et al. Phylogenetic and genomic diversity of human bacteremic Escherichia coli strains. BMC Genomics 2008;9 (1):560.

7. Bachiri T, Lalaoui R, Bakour S, et al. First Report of the Plasmid-Mediated Colistin Resistance Gene mcr-1 in Escherichia coli ST405 Isolated from Wildlife in Bejaia, Algeria. Microbial Drug Resist 2018; 24(7):890-5.

8. Yanat B, Machuca J, Yahia RD, Touati A, Pascual Á, Rodríguez-Martínez J-M. First report of the plasmid-mediated colistin resistance gene mcr-1 in a clinical Escherichia coli isolate in Algeria. Intern J Antimicrob Agent 2016;48(6):760-1.

9. Berrazeg M, Hadjadj L, Ayad A, Drissi M, Rolain J-M. First Detected Human Case in Algeria of $\mathrm{mcr}-1$ Plasmid-Mediated Colistin Resistance in a 2011 Escherichia coli Isolate. Antimicrob Agent Chemother 2016; 60(11):6996-7.

10. Delgado-Blas JF, Ovejero CM, Abadia-Patiño L, Gonzalez-Zorn B. Coexistence of $\mathrm{mcr}-1$ and bla NDM-1 in Escherichia coli from Venezuela. Antimicrob Agents Chemother 2016; 60(10):6356-8.

11. Rossi F, Girardello R, Morais C, et al. Plasmidmediated mcr-1 in carbapenem-susceptible Escherichia coli ST156 causing a blood infection: an unnoticeable spread of colistin resistance in Brazil? Case Reports: Clinics (Sao Paulo) 2017; $72(10): 642-4$

12. Yang R-S, Feng $Y, \operatorname{Lv} X-Y$, et al. Emergence of NDM-5- and MCR-1-Producing Escherichia coli Clones ST648 and ST156 from a Single Muscovy Duck (Cairina moschata). Antimicrob Agents Chemother 2016; 60(11):6899-902.

13. Bernasconi OJ, Kuenzli E, Pires J, et al. Travelers Can Import Colistin-Resistant Enterobacteriaceae, Including Those Possessing the Plasmid-Mediated mcr-1 Gene. Antimicrob Agents Chemother 2016; 60(8):5080-4.

14. Doumith M, Godbole G, Ashton P, et al. Detection of the plasmid-mediated $m c r-1$ gene conferring colistin resistance in human and food isolates of Salmonella enterica and Escherichia coli in England and Wales. J Antimicrob Chemother 2016; 71(8):2300-5. 